\title{
ДОПРОС ПОДОЗРЕВАЕМОГО И СИГНАЛ МОЗГА
}

\section{BRAIN SIGNALS ANALYSIS DURING INTERROGATION OF A SUPEST}

\section{N. Racheva \\ F. Baleevskikh \\ V. Kotov}

Summary: The article discusses issues related to obtaining reliable testimony from a suspect. Various situations are analyzed and recommendations are given on the use of tactical techniques and their complexes aimed at checking the validity of a suspicion. In the event of acute problem-conflict situations, it is possible to use the scientific method of scanning the brain, which allows you to read the thoughts of the suspect. In the future, this will have a tactical significance when interrogating a subject.

Keywords: interrogation, suspect, situations, tactics, whisper of the brain.

\author{
Рачева Нелли Витальевна \\ К.ю.н., дочент, Уральский государственный \\ юридический университет \\ ekaterinburgg@mail.ru \\ Балеевских Федор Валентинович \\ К.ю.н., дочент, Уральский государственный \\ юридический университет \\ Bf61@mail.ru \\ Котов Василий Васильевич \\ К.ю.н., дочент, Уральский государственный \\ юридический университет \\ kotov-1958@inbox.ru
}

Аннотация: В статье рассматриваются вопросы, связанные с допросом подозреваемого и получением от него достоверных показаний. Анализируются различные ситуации и даются рекомендации по использованию тактических приемов и их комплексов, направленных на проверку обоснованности подозрения. При возникновении острых проблемно-конфликтных ситуаций, возможно использование научного метода сканирования головного мозга, позволяющего прочесть мысли подозреваемого. В дальнейшем это будет иметь тактическое значение при допросе субъекта.

Ключевые слова: допрос, подозреваемый, ситуации, тактические приемы, шепот мозга.

фактов, обстоятельств, имеющих значение для расследования совершенного преступления.

усмотренным ст.91 УПК РФ, либо в отношении которого избрана мера пресечения до предъявления обвинения или в отношении которого возбуждено уголовное дело. [1] Подозреваемый должен быть допрошен не позднее 24 часов с момента его фактического задержания (ч.2 ст.46 УПК РФ). С одной стороны, немедленный допрос подозреваемого создает благоприятные условия для получения от него более полных показаний и организации их быстрой проверки. С другой стороны, надо иметь ввиду, что в отношении подозреваемого имеется меньше доказательств и это обуславливает преимущественно разведывательный характер допроса.

В законе закреплены либо общие указания о том, что следователь объявляет подозреваемому, в совершении какого преступления он подозревается, что дает возможность маневрирования имеющейся у следствия оперативной и доказательственной информацией. Это означает, что ситуации, формирующиеся к моменту формулировки подозрения, отличаются меньшей по объему и менее достоверной по качеству информацией о личности заподозренного и совершенном им преступлении.

Допрос есть процесс совместной мыслительной, информационной деятельности, взаимное воздействие допрашиваемого и следователя с целью восстановления
Допрос - это исключительно сложный и противоречивый процесс. Информация, которой обмениваются участники, весьма многообразна. Дело в том, что понятие информации при допросе значительно более емкое, чем только словесное описание фактов, событий допрашиваемым. Информация содержится и передается внешним обликом допрашиваемого лица, особенностями его речи, его психическим состоянием и т.д.

Можно сказать, что получаемая при допросе информация классифицируется на два вида: информация о произошедшем и интересующим следствие событии, факте и информация об источнике передачи сообщения об этих фактах, событиях (состояние и поведение допрашиваемого, его реакции и др.). Информация второго вида дает следователю возможность правильно оценить источник передачи информации и избрать соответствующие тактические приемы, которые позволят получить от допрашиваемого более полные, объективные сведения, добиться от него воспоминания и полного изложения известных ему фактов.

Однако, получить эту информацию бывает не так иной степени определяет линию своего поведения на легко. Подозреваемый еще перед допросом в той или 
предстоящем следственном действии. В связи с чем, его реакции, поведение могут не соответствовать его действительному отношению к произошедшим фактам, событиям. В соответствии с этим, допрос есть процесс решения мыслительной задачи о действительной сущности источника передачи сведений-допрашиваемом лице.

При допросе подозреваемого, во всех случаях, необходима его активная мыслительная деятельность для связного изложения всех элементов модели произошедшего события. В свою очередь, мыслительная деятельность в значительной степени зависит от психического состояния допрашиваемого (плохое настроение тормозит мыслительные процессы, страх парализует их). Именно поэтому, следователь должен устанавливать перед началом допроса психологический контакт с допрашиваемым и поддерживать его в ходе всего следственного действия. Следует также отметить, что на допросе субъект стремится получить информацию и от следователя для того, чтобы восполнить недостающие у него сведения о том, чем реально располагает следствие, какие есть доказательства, об участии допрашиваемого в совершенном преступлении. Именно эта особенность часто определяет активность подозреваемого на допросе и направленность с его стороны различных вопросов.

При допросе подозреваемых следователь должен учитывать факторы, влияющие на выбор и реализацию тактических приемов: сложившуюся следственную ситуацию; наличие, вид и объем имеющихся доказательств причастности заподозренного к преступному событию; оперативные данные и сведения о свойствах личности и состоянии лица на момент задержания. В некоторых случаях следователи не уделяют должного внимания сбору информации о личности подозреваемого. Подобную ситуацию нельзя признать правильной, ибо такая информация в большинстве случаев способствует не только проведению допроса, но и раскрытию преступления. [2]

Получить сведения о свойствах личности подозреваемого возможно следственным путем (допросы в качестве свидетелей его соседей, сослуживцев и близких), при производстве проверочных действий (изучение личных дел по месту работы, учебы, отбывания наказания и т.д.) и оперативно-розыскных мероприятий.

Изучение личности подозреваемого направлено на выяснение его интеллектуальных способностей (возможность оценить свои поступки, делать соответствующие выводы, излагать мысли и т.д.) и морально-волевых качеств (раскаяние, страх наступления уголовной ответственности, умение скрывать свои реакции и др.). Определенную информацию о некоторых свойствах личности допрашиваемого можно получить при осмотре места происшествия. Так, А. и К. ночью ворвались в дом пред- принимателя, связали и били его железным прутом по голове. С целью поиска денег пытали его, ставя утюг на спину. [3] Проявление такой жестокости позволяет предположить, что подозреваемые эгоистичны, хладнокровны и склонны к оказанию противодействия.

Подготовка к допросу подозреваемого заключается не только в изучении материалов уголовного дела, но и прогнозировании возможных вариантов его поведения, оказания им противодействия и выборе способов их преодоления. Составление письменного плана целесообразно в любых ситуациях, что позволит следователю маневрировать тактическими приемами в различных сочетаниях и их последовательности.

С тактических позиций допрос подозреваемого следует начинать в форме свободного рассказа. Таким образом, допрашиваемый не сможет получить информацию об объеме и характере осведомленности следователя. Просьба подозреваемого о том, чтобы ему задавали вопросы, является уловкой с целью выяснить, что известно следователю о преступной деятельности допрашиваемого. Однако, в ходе первого допроса сразу получить ответы на все интересующие следствие вопросы будет проблематично. Поэтому по окончании свободного рассказа рекомендуется переходить к вопросно-ответной форме допроса. Так, при расследовании краж, совершенных группой под руководством П. последний, умолчал об эпизоде проникновения в коттедж, расположенный недалеко на одной из центральных улиц города. После того, как следователь спросил, где группой были совершены другие кражи, П. назвал еще и несколько разбойных нападений, о которых следствию не было известно. [4]

К моменту допроса подозреваемых складываются простые и сложные ситуации. В случаях, когда подозреваемый полностью подтверждает правильность возникшего в отношении его подозрения, на допросе возникают бесконфликтные ситуации. Кроме того, вина подозреваемого подтверждается и другими материалами дела. При признании подозреваемым своей вины рекомендуется использование приемов детализации показаний; разъяснение значения активного способствования раскрытию преступления и изобличения других соучастников преступления (ст.61 УК РФ); использование положительных свойств личности; постановки контрольно-проверочных вопросов с целью выявить подлинную позицию допрашиваемого.

Однако, как показывает анализ судебно-следственной практики, большинство подозреваемых не признают свою вину не только в момент задержания, но и на различных стадиях и этапах досудебного производства. При этом возникают довольно сложные ситуации, особенно в тех случаях, когда совершение преступления не 
наблюдали очевидцы (свидетели), подозреваемые ранее судимы либо не знакомы потерпевшему. Обнаруженные на них следы объясняют различными нейтральными причинами. Поэтому при допросе в таких ситуациях, целесообразно использовать приемы детализации показаний [5] для выяснения обстоятельств возникновения, обнаруженных у подозреваемого следов, а также приема указания на выявленные противоречия с пояснением, что такие следы не могли образоваться при реальных обстоятельствах совершенного преступления.

В ситуациях отрицания подозреваемым своей вины в совершенном преступлении рекомендуется детально зафиксировать любые его показания, подробно выяснить, где он был и что делал в период, предшествующий расследуемому событию, в момент совершения посягательства и в последующий период, вплоть до задержания. Кроме того, важно выявить круг лиц, которые могут подтвердить показания подозреваемого. В таких случаях следует получить предельно детализированные показания, отражающие подробности событий и действий допрашиваемого.

Но некоторые следователи ограничиваются записью в протоколе допроса фразами общего характера и не реализуют те тактические приемы, которые позволят убедить подозреваемого в бесперспективности занимаемой им негативной позиции, например, использование положительных качеств личности (можно указать, что близкие и знакомые характеризуют его как выдержанного, честного человека, способного управлять своим поведением), постановка контрольных и уточняющих вопросов, допущение «легенды», пресечение лжи.

Возможна реализация приема создания у конфликтующего субъекта представления о большей осведомленности следователя. Суть этого приема заключается в неоднократных ссылках на одни и те же доказательства, но излагаемые с помощью разных лексических средств и в различных сочетаниях. [6]

Наряду с учетом индивидуальных особенностей личности подозреваемого, выявленных противоречий в его показаниях и получения достоверных, полных показаний необходимо использовать доказательства. Однако из-за их небольшого объема на данном этапе расследования, основную тактическую роль играют криминалистический анализ и предельная детализация показаний. Как правило, подозреваемый, задержанный вскоре после совершения преступления, не в состоянии правдоподобно продумать все детали ложной версии произошедшего события. И использование во время допроса детализации (конкретизации) показаний, а также допущение легенды позволят опровергнуть ложные показания допрашиваемого.
Возникают ситуации, когда подозреваемый отрицает свою причастность к преступлению и выдвигает ложное алиби. В таких случаях следователю предстоит доказать факт нахождения лица на месте преступления в момент его совершения. При этом, в ходе допроса следует предельно подробно выяснить о месте нахождения субъекта в момент совершения общественно опасного деяния, происходивших там событий и его участниках. Целесообразно использовать приемы детализации и допущения легенды, проводить анализ показаний с целью выявления возникших противоречий и затем выяснить их причины. Как правило, это вынуждает подозреваемого отказаться от ложного алиби и прекратить противодействие следствию.

При совершении преступления группой лиц, перед следователем стоит задача, индивидуализировать роль каждого подозреваемого, что имеет важное тактическое значение. Первым рекомендуется допрашивать более «слабое звено», т.е. того из задержанных, кто конфликтует с соучастниками, выполняет в группе второстепенные роли, ранее не был судим. Если определить такое лицо сложно, то следователю для решения вопроса о последовательности допроса нескольких подозреваемых, необходимо предложить каждому охарактеризовать других соучастников группы, не затрагивая наиболее существенных обстоятельств расследуемого события. [7] В некоторых ситуациях возможно стимулирование принятия решения об отказе противодействия посредством использования чувства неуверенности, страха допрашиваемого. [8] При допросе следует учитывать наличие судимостей, особенности характера каждого подозреваемого, степень доказанности участия допрашиваемого в конкретном эпизоде и взаимоотношения между членами группы.

Судебно-следственная практика показывает, что при проведении допросов лиц, совершивших преступление в группе целесообразно использовать противоречия в показаниях задержанных (внешние противоречия); разъяснить допрашиваемому, отказывающемуся от дачи показаний, что ему выгоднее дать достоверные показания, чем ждать, когда остальные соучастники попытаются переложить на него свою вину; метод «косвенного допроса»; допрос по схеме «вопрос-ответ»; использование положительных свойств личности допрашиваемого; допрос двумя следователями (членами следственной группы).

Во многих ситуациях при допросе подозреваемых, следователь должен применять приемы допроса в различном сочетании, уметь варьировать ими и использовать методы изобличения.

Острые проблемно-конфликтные ситуации складываются при расследовании неочевидных преступлений, 
совершение которых не наблюдали свидетели-очевидцы; серийных убийств, когда подозреваемый был задержан благодаря случайному стечению обстоятельств; иных тяжких преступлений. Речь идет о тех ситуациях, где наибольшая трудность связана с установлением виновных лиц и латентным характером информации в результате их умышленных действий.

В таких условиях подозреваемый отказывается от дачи показаний, полагая, что следствие может располагать лишь косвенными доказательствами его причастности к преступлению. Однако, при совершении субъектом преступления, его мозг сохраняет преступное деяние как воспоминание. И возникает задача, как с помощью научных методов выявить это воспоминание и затем получить от подозреваемого достоверные показания и изобличить его в совершенном преступлении.

Американскими учеными разработана технология определения степени виновности подозреваемого в преступлении с помощью сканирования головного мозга. Основателем этой разработки является профессор Ларри Фарвелл. [9] Данная технология основана на научном подходе и не имеет отношения к проявлению эмоций человека, не зависит от его психологического состояния, а также состояния его здоровья. Суть компьютерной «дактилоскопии» мозга позволяет выявить скрываемую информацию при демонстрации лицу ключевых слов и фраз, фотоснимков с места происшествия, предъявлении вещественных улик.

Все это мелькает на экране компьютера, который регистрирует электромагнитные волны, испускаемые мозгом на то, что видит испытуемый. Реакция мозга записывается в виде диаграммы, анализируя которую можно определить, узнает ли испытуемый то, что он видит. Система сканирования мозга математически анализирует волновые реакции мозга и определяет «информация присутствует» или «информация отсутствует» в памяти в связи с образом (предметами, словами, фотоснимками). И если действительно испытуемый совершил преступление, то его мозг выдает определенный сигнал, который анализируется. Самое важное заключается в том, что данный процесс по- дозреваемый не может контролировать.

Изображения на экране влияют на активность мозга. И так называемый «шепот» мозга - есть увеличение активности мозга в случае, если видеоряд знаком испытуемому, т.е. надо прочесть мысли преступника. При этом следует тщательно подготовиться и подобрать список аббревиатуры, а мозг всегда отвечает. Это гарантирует объективность. Увидев, например, орудие убийства, мозг и подозреваемого и свидетеля могут среагировать «шепотом» (в их памяти одинаковая информация) и чтобы понять, кто из них совершил преступление, следует затем тактически правильно задавать вопросы.

Однако данная методика подвергается критике со стороны российских криминалистов, которые считают электросигнал мозга неприемлимым при расследовании преступлений. Конечно, данная технология не может признаваться даже в качестве косвенного доказательства виновности подозреваемого в совершенном преступлении. В то же время, такая методика вполне может иметь тактическое значение при дальнейшем допросе подозреваемого, особенно в острых проблемно-конфликтных ситуациях. У следователя уже будет информация, что субъект отреагировал - соответствующий сигнал мозга был зафиксирован датчиками. И дальнейшее применение в ходе допроса тактических приемов и их комплексов позволит получить от подозреваемого достоверные показания.

Еще следует сказать о том, что дактилоскопия мозга по сравнению с полиграфом является более точным методом, поскольку испытуемый не имеет никакой возможности контролировать электромагнитные импульсы мозга. Полиграф регистрирует лишь стрессовые или эмоциональные реакции лица (ритмы дыхания, сердцебиение и кожно-гальванические реакции). Дактилоскопия не вдается в детали, а лишь определяет наличие информации в памяти испытуемого, который лжет. В дальнейшем дактилоскопия мозга позволит установить истину и сформировать доказательственную базу по изобличению подозреваемого в совершении преступления.

\section{ЛИТЕРАТУРА}

1. Уголовно-процессуальный кодекс Российской Федерации СПс Консультант Плюс [Электронный ресурс.] Режим доступа: http://www.consultant.ru/ document/cons_doc_LAW_34481/fc540be541e9bda8295f240e0954d96b885bdaf5/

2. Карагодин В.Н. Основы методики расследования умышленных убийств. Учебное пособие. Екатеринбург, 2010. С.170.

3. Архив Тюменского областного суда. Уголовное дело № 2-12/2016.

4. Архив Калининградского областного суда. Уголовное дело № 2-4/2013.

5. Селиванов Н.А. Допрос и очная ставка //Леви А.А., Пичкалева Г.И., Селиванов Н.А. Получение и проверка показаний следователем. М., 1987. С.15.

6. Карагодин В.Н. Методика расследования должностных преступлений. Учебное пособие. Екатеринбург, 2013. С. 118.

7. Глазырин Ф.В. Изучение личности обвиняемого и тактика следственных действий. Свердловск, 1973. С.100. 
8. Балеевских Ф.В., Котов В.В. Особенности взаимодействия следователя с органом дознания в целях использования убеждения для преодоления взаимодействия допрашиваемого. / Вопросы Российской юстиции, 2015. №1. С. 9.

9. Фарвелл, Лос-Анджелес (2013). Обнаружение лжи. В Энциклопедии судебных наук, 2-е издание. Оксфорд: Эльзевир.

\section{○ Рачева Нелли Витальевна (ekaterinburgg@mail.ru ), Балеевских Федор Валентинович (Bf61@mail.ru,} Котов Василий Васильевич (kotov-1958@inbox.ru).

Журнал «Современная наука: актуальные проблемы теории и практики»

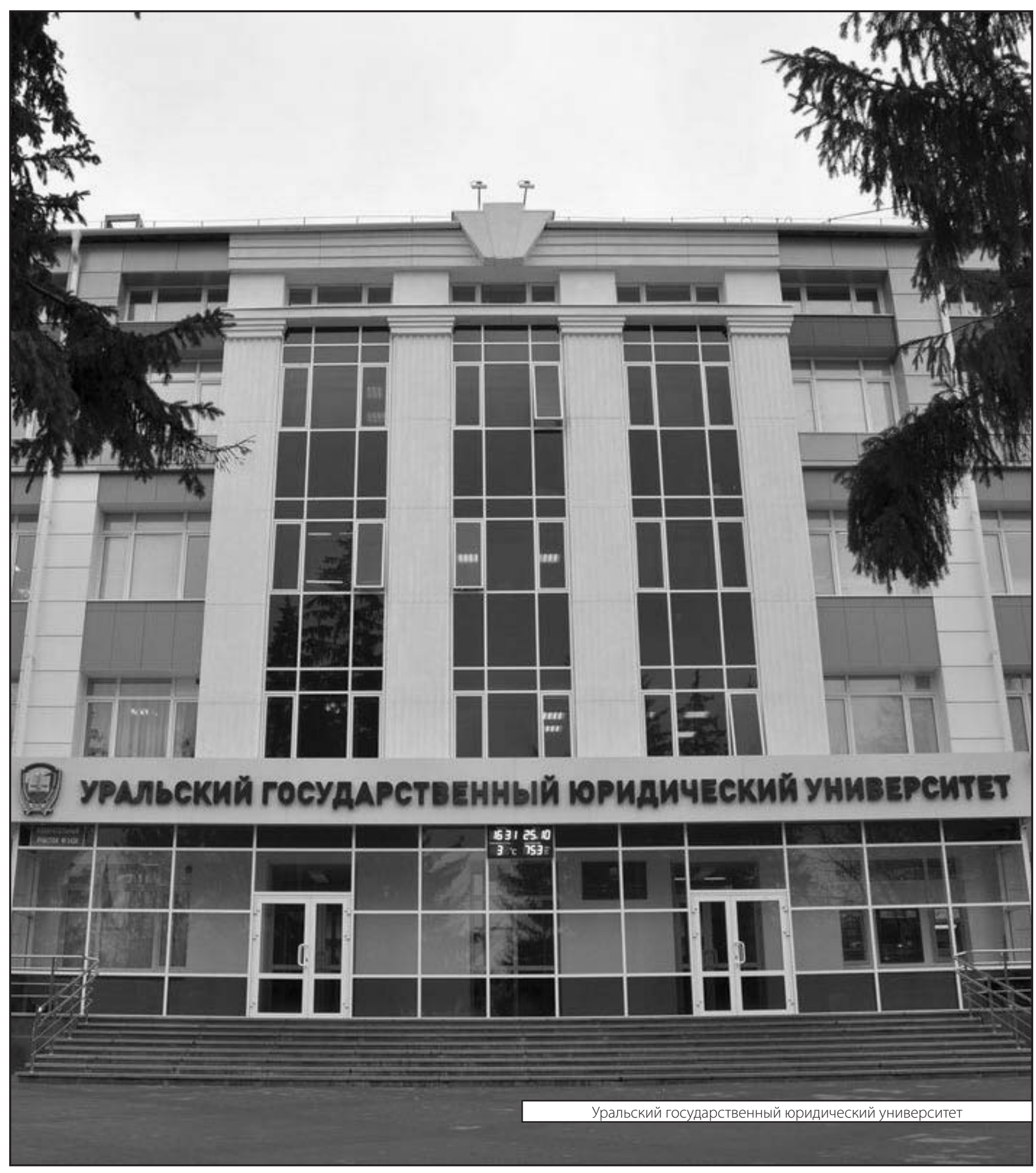

